Global Conferences Series:

Social Sciences, Education and Humanities (GCSSSEH), Volume 6, 2020

International Conference Fakultas Tarbiyah dan Keguruan Universitas Islam Negeri Imam Bonjol Padang (ICFTKUINIBP) 2019

DOI: https://doi.org/10.32698/icftk393

\title{
STEAM Learning Development in the 2013 Curriculum for Early Childhood Education
}

\section{Pengembangan Pembelajaran STEAM Kurikulum 2013 untuk Pendidikan Anak Usia Dini}

\author{
Kartika Metafisika ${ }^{a}$, Ratna Pangastuti ${ }^{\mathrm{a}}$ \\ ${ }^{a}$ Sekolah Tinggi Agama Islam Taruna Surabaya, Indonesia \\ E-mail: kartikametafisika1@gmail.com
}

\begin{abstract}
Early Childhoods have a curiosity about the surrounding environment. This time, they are also the alpha generation who will enter the 4.0 industrial revolution who required to think critically, communicate, collaborate, be creative and have skills in mastering technology that can be trained and facilitated through the STEAM approach. STEAM for Early Childhood combines Science, Technology, Engineering, Art and Mathematics with a simple context and is close to everyday life, which is a learning approach that is relevant to the 2013 curriculum because it is in line with the scientific approach. The need to develop STEAM content and approaches referring to the 2013 curriculum can facilitate early childhood educators to develop STEAM learning according to the 2013 curriculum. Therefore, the STEAM learning development design in the 2013 curriculum is produced through the Research and Development method accompanied by a prototype of the development results.
\end{abstract}

Keywords: STEAM approach, early childhood education, mathematics and science for early childhood

\section{INTRODUCTION}

Usia 0-6 tahun saat ini merupakan generasi alfa yang akan memasuki revolusi industri 4.0. Kemampuan yang mereka miliki untuk menggali informasi secara mandiri dan beradaptasi dengan teknologi yang berkembang sangat cepat (Ramadlani \& Wibisono, 2017) adalah tantangan yang harus dihadapi oleh para pendidik untuk mengembangkan keterampilan abad 21 yakni berpikir kritis, komunikasi, kolaborasi, kreatifitas, keterampilan menguasai teknologi, informasi dan media (Kemendikbud, 2015b). Dekatnya kehidupan Anak Usia Dini (AUD) dengan teknologi menjadi harapan bahwa di masa mendatang mereka tidak hanya pintar sebagai pengguna tetapi juga dapat menjadi pelopor perkembangan teknologi.

Anak Usia Dini juga memiliki rasa ingin tahu yang tinggi terhadap lingkungan sekitar mereka (Sharapan, 2012). Hal tersebut dapat diupayakan dengan aktivitas yang dapat mengenalkan AUD dengan ilmu yang melandasi perkembangan teknologi mulai dari hal yang sederhana serta bagaimana proses pembelajaran tersebut dapat mengarahkan anak terlatih untuk berpikir dan memiliki sikap ilmiah melalui pendekatan STEAM.

STEAM (Science, Technology, Engineering, Art, dan Mathematics) merupakan pendekatan pembelajaran dengan memanfaatkan sains, teknologi, teknik, seni dan matematika secara terpadu berpusat pada anak didik yang sudah dikembangkan di berbagai negara mulai tingkat Pra sekolah hingga Sekolah Menengah Atas. Pendekatan STEAM pada AUD bertujuan untuk meningkatkan keterampilan berpikir tingkat tinggi dan juga keterampilan motorik pada anak didik yang menekankan pada proses pembelajaran dibandingkan pada hasil belajar melalui aktivitas hands on (Thuneberg et al., 2018). Selain itu istilah

Copyright (C) 2020, the Authors. Published by Redwhite Press. 
STEAM berkembang dari pembelajaran STEM (Science, Technology, Engineering, Mathematics) dengan memasukkan unsur seni (Art) agar pada praktek pembelajaran STEAM anak bebas bereksplorasi untuk mengembangkan keterampilan berpikir kreatif dan inovasi (DeJarnette, 2018). Penerapan STEAM di Indonesia sangat relevan dengan Kurikulum 2013 (K13) karena sejalan dengan proses pembelajaran standar K13 dengan pendekatan saintifik (Kemendikbud, 2015b) yakni mengajak anak didik untuk mengamati, menanyakan, mengumpulkan informasi, menalar, dan mengomunikasikan. Sehingga pemerintah sudah menyosialisasikan pembelajaran STEAM di Indonesia dengan pendekatan Problem Based Learning menggunakan media Loose Part kepada perwakilan guru-guru PAUD se-Indonesia oleh Dirjen GTK PAUD (PPPPTK \& PLB, 2020).

Kurikulum 2013 yang perlu dilaksanakan secara terpadu dengan metode saintifik sangat sejalan dengan konsep pembelajaran STEAM. Dalam penerapan STEAM pada pembelajaran tematik PAUD, prinsip yang perlu dipegang dalam pengembangan tema adalah 1) Kedekatan, 2) Kemenarikan, 3) Kesederhanaan, 4) dan Keinsidentalan. Selain itu cara untuk penentuan tema, sub-tema, hingga materi pembelajaran dapat dilakukan dengan mengamati alam sekitar, memperhatikan sosial budaya, serta memperhatikan minat dan kesukaan anak (Kemendikbud, 2015a). Dengan memperhatikan prinsip dan cara pengembangan tema mengacu pada Kurikulum 2013 maka pembelajaran STEAM harus memperhatikan perkembangan anak usia dini, hal-hal yang teramati oleh AUD, dan berpusat pada minat dan kesukaan mereka disesuaikan dengan kekhasan pembelajaran STEAM yakni kegiatan yang memiliki muatan sains, teknologi, matematika, dan engineering secara terpadu dan melibatkan anak untuk memecahkan masalah atau mendapatkan kesimpulan dari yang mereka pelajari.

STEAM untuk Anak Usia Dini menurut Sharapan (2012) memiliki definisi sebagai berikut:

1. Science. Science (Sains) adalah mengembangkan rasa penasaran anak terhadap lingkungan sekitar. Pertanyaan tentang "Mengapa es mencair?",'Mengapa ada angin berhembus?" yang menjadi bagian dari pertanyaan investigasi dan eksperimen.

2. Technology. Teknologi merupakan istilah lain dari alat. Alat yang digunakan untuk membuat sesuatu yang lebih berdaya guna. Tidak hanya teknologi seperti smartphone dan mesin saja, tetapi alat seperti pensil, pulpen, penggaris, timbangan, sekop, dan lain-lain sebagai alat untuk membuat sesuatu atau menyelesaikan masalah.

3. Engineering. Engineering (teknik) adalah identifikasi permasalahan dalam upaya menciptakan sesuatu berdaya guna. Sebagai contoh bagaimana agar bangunan rumah-rumahan dari lego yang ingin dibangun dapat berdiri tegak? Bagaimana agar mobil-mobilan yang ingin dibuat bisa maju ke depan?

4. Art. Art (seni) mengacu pada bagaimana anak menuangkan ide untuk membuat sesuatu sesuai imajinasinya. Misalnya dengan menggambar bentuk, membuat grafik, atau membuat model.

5. Mathematics. Mathematics (matematika) tidak hanya menghitung saja tetapi juga melibatkan bagaimana anak membandingkan, memilih, membuat pola, atau identifikasi bentuk. Dibutuhkan langkah-langkah untuk menginisiasi pengenalan matematika untuk AUD sesuai tahap perkembangannya (Cross et al., 2009).

Dibutuhkan adaptasi dalam mengubah kebiasaan mengajar secara tradisional menjadi berpusat pada anak sehingga anak mampu mengomunikasikan hasil ciptaannya berdasarkan desain yang mereka kembangkan. Sebagai dasar kemampuan menerapkan STEAM di kelas, guru perlu memiliki kemampuan untuk mengidentifikasi unsur-unsur STEAM yang dapat dieksplorasi dari tema yang telah ditentukan mengacu pada K13 dan guru juga perlu memiliki pijakan dalam memahami produk sains yang dapat muncul dari konteks sehari-hari. Kurangnya kemampuan guru PAUD dalam melaksanakan pembelajaran sains sebagai proses atau sains sebagai produk (Garbett, 2003) secara kontekstual (Winarni, 2017) dan guru-guru merasa bahwa anak usia dini belum mampu menangkap konsep sains (Saçkes, 2014) menjadi permasalahan pembelajaran STEAM di kelas padahal sains merupakan pijakan dari pembelajaran STEAM baik sebagai proses maupun produk yang kemudian dikaitkan dengan empat disiplin ilmu lainnya (DeJarnette, 2018).

Kemampuan calon guru PAUD untuk mengidentifikasi unsur-unsur STEAM yang dapat dieksplorasi dari tema mengacu pada Kurikulum 2013 dan kemampuan guru mengeksplorasi pertanyaan dan eksplanasi sains menjadi pijakan penting untuk membangun kemampuan mereka mendesain pembelajaran STEAM AUD. Selain itu guru PAUD untuk mengembangkan keterampilan tingkat tinggi AUD, guru perlu mengeksplorasi kemampuan untuk mengelaborasi pertanyaan open ended yang dapat dipahami AUD dan mendesain pembelajaran STEAM yang bermuara pada kepercayaan diri calon guru PAUD untuk menerapkan sains dalam pembelajaran (Saçkes, 2014) secara kontekstual. Dengan demikian peneliti ingin meneliti bagaimana desain dan penerapan desain pengembangan pembelajaran STEAM mengacu pada Kurikulum 2013. 
Desain "Pengembangan Pembelajaran STEAM AUD Kurikulum 2013" ini dikembangkan dengan tujuan menggali kreatifitas guru PAUD dan calon guru PAUD untuk menganalisis secara mandiri pertanyaan STEAM PBL yang dapat dikemukakan kepada anak dan bagaimana jawaban yang diharapkan muncul pada anak. Selain itu, guru PAUD dapat mengeksplorasi hal-hal disekelilingnya untuk dimanfaatkan dalam pembelajaran STEAM.

\section{METHOD}

Penelitian ini merupakan bagian dari Research and Development untuk pengembangan desain pembelajaran sains dan matematika untuk Anak Usia Dini. Pertama-tama peneliti melakukan analisis kebutuhan. Berdasarkan hasil studi pendahuluan, peneliti merancang desain pengembangan pembelajaran STEAM mengacu pada pedoman pengembangan tema Kurikulum 2013. Berdasarkan desain tersebut dilakukan pengembangan desain Pembelajaran STEAM dalam Kurikulum 2013 Pendidikan Anak Usia Dini disertai penerapannya.

\section{HASIL DAN DISKUSI}

Berdasarkan hasil analisis kebutuhan, diketahui bahwa pembelajaran sains di beberapa TK di Surabaya selama ini belum memberikan kontribusi pada keterampilan berikir HOTS. Kegiatan eksperimen yang dilaksanakan di sekolah hanya terbatas pada apa yang siswa dapat lakukan melalui percobaan namun guru tidak mempertanyakan mengapa fenomena tersebut dapat terjadi. Padahal pertanyaan yang diajukan oleh guru merupakan pijakan pada keterampilan berpikir anak dan perlu menjadi perhatian dalam penyusunan desain pembelajaran hingga Rancangan Pembelajaran RPPH.

Pembelajaran STEAM saat ini sudah mulai terlihat trennya di Indonesia dilihat dari diadakannya pelatihan STEAM yang dilaksanakan oleh Mendikbud kepada guru TK. Pembelajaran STEAM yang dirintis di Indonesia mengadaptasi pada pendekatan Problem Based Learning (PBL) dengan Loose Part sebagai media yang disosialisasi oleh PPPPTK dan PLB Kemendikbud kepada guru-guru PAUD se- Indonesia. Meskipun demikian, banyak media selain loose part yang dapat digunakan dengan tujuan untuk mengasah keterampilan berpikir tingkat tinggi pada anak. STEAM sendiri tidak harus selalu mengaitkan seluruh unsur STEAM dalam satu kegiatan pembelajaran (Becker \& Park, 2011) sehingga pembelajaran STEAM tidak terbatas pada membuat sesuatu, tetapi juga dapat dilakukan dengan melakukan investigasi terhadap apa yang terjadi di sekitar yang mengaitkan berbagai disiplin ilmu secara terpadu untuk menyelesaikan masalah.

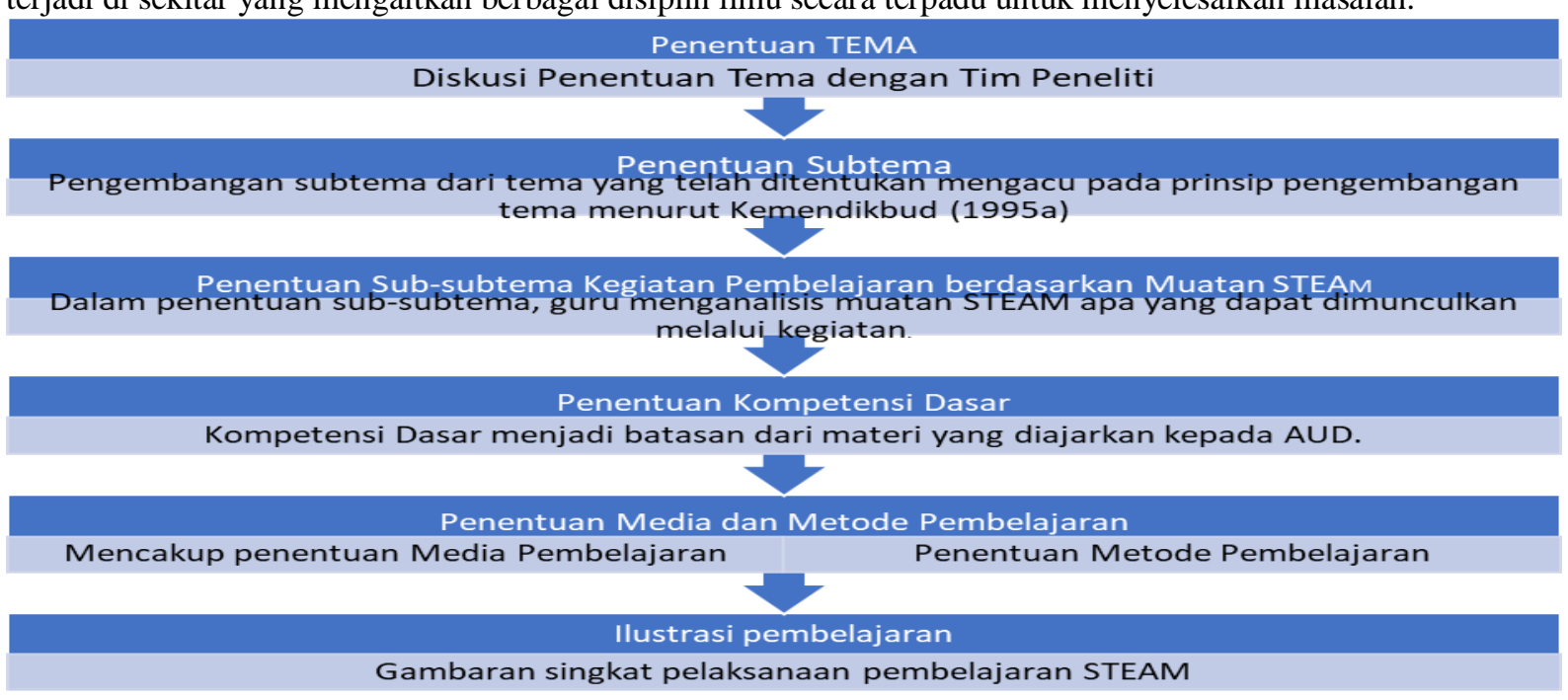

Gambar 1. Desain "Pengembangan Pembelajaran STEAM AUD Kurikulum 2013"

Proses mengembangkan muatan STEAM dalam pelaksanaan kurikulum 2013 PAUD ada pada penentuan sub-subtema serta materi pelajaran dan penentuan kompetensi dasar menjadi pedoman cakupan keluasan dan kedalaman materi STEAM. Dalam proses penentuan materi pembelajaran, guru perlu memiliki bekal ilmu yang memadai untuk mengetahui muatan-muatan Science, Technology, Engineering, Art dan Mathematics yang muncul dari satu atau lebih kegiatan pembelajaran yakni dengan menganalisis pertanyaan yang akan ditanyakan kepada anak dalam pembelajaran serta mencari jawabannya dari berbagai literatur. 
Pembelajaran matematika harus sesuai tahap-tahap perkembangan AUD dalam memahami simbol-simbol matematika dan operasinya (Cross et al., 2009). Pada Tabel 1 adalah contoh dari penerapan Pengembangan STEAM untuk AUD:

Tabel 1. Prototype Penerapan Desain

"Pengembangan Pembelajaran STEAM AUD Kurikulum 2013"

\begin{tabular}{l|l}
\hline Sasaran Peserta Didik & TK B (5-6 tahun) \\
\hline Tema & Alam Semesta \\
\hline Subtema & Bumi \\
\hline Sub-subtema & Udara \\
\hline Kegiatan Pembelajaran & Membuat Parasut \\
\hline Analisis Unsur STEAM &
\end{tabular}

Science

Mengapa parasut bisa terbang? Karena ada udara atau ada angin. Parasut tertahan oleh udara sehingga hambatan dari udara tersebut dapat membuat parasut melayang-layang sebelum sampai ke tanah.

Anak diminta memilih bahan mana yang cocok untuk membuat parasut. Misalnya anak diminta memilih mana yang paling tepat untuk pembuatan parasut (contoh: kain tebal, plastic kresek tipis, jaring-jaring).

Jika bahan parasut mini menggunakan jaring berlubang apakah parasut bisa terbang? Tidak bisa terbang karena angin bisa masuk ke sela-sela lubang

Technology

\section{Engineering}

Art

Mathematics sehingga tidak ada hambatan yang membuat bahan jaring tersebut untuk terbang.

Apakah parasut mini yang dibuat dari kain tebal bisa terbang? Bisa tapi anginnya harus kencang sekali, kalau tidak ada angin, parasut akan jatuh begitu saja.

Alat dan bahan apa yang dibutuhkan untuk membuat parasut? Plastik kresek, tali, gunting, bandul kecil.

Bagaimana cara agar parasut bisa terbang? Bisa diterbangkan di udara terbuka atau didekatkan dengan kipas angin.

Bagaimana penempatan tali pada parasut agar parasut bisa melayang-layang dengan baik? Dengan menempatkan tali pada parasut dengan jarak yang sama satu sama lain.

Bagaimana proses kreatif yang dapat muncul ketika membuat parasut? Anak dapat menghias atau menggunting bentuk parasut dengan bentuk geometri sesuai imajinasi.

Bagaimana menentukan panjang tali, dan berapa banyak tali yang dibutuhkan untuk mengaitkan parasut dengan bandul? Panjang tali harus sama satu sama lain dan dapat diukur menggunakan alat ukur baku (penggaris) maupun tidak baku (jengkal masing-masing anak).

Kompetensi Dasar

3.3 Mengenal anggota tubuh, fungsi, dan gerakannya untuk pengembangan motorik kasar dan motorik halus

4.3 Menggunakan anggota tubuh untuk pengembangan motorik kasar dan halus 
Indikator: Melakukan kegiatan yang menunjukkan anak mampu terampil menggunakan tangan kanan dan kiri dalam berbagai aktivitas (misal: mengancing kan baju, menali sepatu, menggambar, menempel menggunting, makan)

1.5 Mengetahui cara memecahkan masalah seharihari dan berperilaku kreatif.

4.5 Menyelesaikan masalah sehari-hari secara kreatif

Indikator: Mampu memecahkan sendiri masalah sederhana yang dihadapi

1.6 Mengenal benda-benda disekitarnya (nama, warna, bentuk, ukuran, pola, sifat, suara, tekstur, fungsi, dan ciri-ciri lainnya.

4.6 Menyampaikan tentang apa dan bagaimana benda-benda di sekitar yang dikenalnya (nama, warna, bentuk, ukuran, pola, sifat, suara, tekstur, fungsi, dan ciri-ciri lainnya) melalui berbagai hasil karya.

Indikator: Melakukan kegiatan yang menunjukkan anak mampu mengenal benda dengan mengelompokkan berbagai benda di lingkungannya berdasarkan ukuran, pola, fungsi, sifat, suara, tekstur, fungsi, dan ciri-ciri lainnya.

3.8 Mengenal lingkungan alam (hewan, tanaman, cuaca, tanah, air, batubatuan, dll)

4.8 Menyajikan berbagai karya yang berhubungan dengan lingkungan alam (hewan, tanaman, cuaca, tanah, air, batu-batuan, dll) dalam bentuk gambar, bercerita, bernyanyi, dan gerak tubuh.

Indikator:

- Menceritakan peristiwa-peristiwa alam dengan melakukan percobaan sederhana

- Mengungkapkan hasil karya yang dibuatnya secara lengkap/ utuh yang berhubungan dengan benda-benda yang ada di lingkungan alam.

3.9 Mengenal teknologi sederhana (peralatan rumah tangga, peralatan bermain, peralatan pertukangan, dll).

4.9. Menggunakan teknologi sederhana untuk menyelesaikan tugas dan kegiatannya (peralatan rumah tangga, peralatan bermain, peralatan pertukangan, dll)

Indikator: Melakukan kegiatan dengan menggunakan alat teknologi sederhana sesuai fungsinya secara aman dan bertanggung jawab.

3.15. Mengenal berbagai karya dan aktivitas seni

4.15 Menunjukkan karya dan aktivitas seni dengan menggunakan berbagai media

Indikator: Menghargai penampilan karya seni anak lain (misal dengan bertepuk tangan dan memuji)

3.11Memahami bahasa ekspresif (mengungkapkan 


\begin{tabular}{l} 
Metode Pembelajaran \\
\hline Media Pembelajaran
\end{tabular}

bahasa secara verbal dan non verbal).

4.11 Menunjukkan kemampuan berbahasa ekspresif (mengungkapkan bahasa secara verbal dan non verbal)

Indikator:

- Mengungkapkan keinginan, perasaan, dan pendapat dengan kalimat sederhana dalam berkomunikasi dengan anak atau orang dewasa

- Mengungkapkan perasaan, ide dengan pilihan kata yang sesuai ketika berkomunikasi.
Ilustrasi Kegiatan
Bercerita, bercakap-cakap, eksperimen, penugasan.

- Buku cerita yang memiliki muatan tentang konsep udara/angin.

- Alat yang dibutuhkan untuk eksperimen pembuatan parasut: gunting dan lem

- Bahan yang dibutuhkan untuk eksperimen pembuatan parasut: kain tebal, kain berjaring, plastik kresek, benang, bandul kecil.

- Anak mendengarkan cerita guru tentang udara dan sifatnya.

- Anak diminta untuk mengungkapkan apa yang mereka rasakan ketika mereka terkena angin.

- Anak diperlihatkan tentang gambar orang sedang terjun payung. Lalu bu guru bertanya: Apa yang terjadi jika orang ini terjun tanpa parasut? Mengapa dengan adanya parasut orang ini selamat sampai di darat?(science)

- Anak diminta memprediksikan jika mereka membuat parasut mini, bahan apa yang mereka pakai?apakah plastic kresek, handuk, atau kain berjaring? (science)

- Anak diminta membuat parasut dari bahan yang mereka pilih dengan pertimbangan mereka sendiri.

- Anak menggunting parasut sesuai keinginan (seni)

- Guru bertanya tentang apakah panjang tali untuk mengaitkan parasut dengan bandul harus sama?(engineering)

- Dimana sajakah tali dapat disematkan pada parasut agar parasut bisa melayang-layang di udara?(engineering).

- Guru meminta semua anak mengapresiasi hasil karya yang telah dibuat oleh teman- 


\section{temannya.(seni)}

- Uji coba parasut dengan menerbangkan parasut yang dibuat oleh anak.

- Guru meminta anak mengambil kesimpulan mengenai parasut dengan bahan apa yang dapat terbang dengan baik? Bahan terbaik adalah plastik kresek karena tipis sehingga dapat tertahan lebih lama di udara, sedangkan yang berjaring tidak bisa terbang karena udara tidak tertahan pada bahan tersebut, sedangkan untuk bahan handuk susah terbang kecuali jika ada angin sangat kencang.

- Guru meminta siswa mengamati panjang tali yang disematkan antara bandul dengan parasut. Jika panjangnya berbeda-beda, maka parasut tidak dapat melayang dengan baik.

- Guru meminta siswa mengamati pada sudut mana saja anak menyematkan tali agar anak memahami bahwa semakin simetris penempatan tali pada parasut akan membuat parasut lebih lama melayang di udara.

\section{SIMPULAN DAN REKOMENDASI}

Berdasarkan hasil analisis kebutuhan diketahui bahwa pelatihan STEAM dengan pendekatan $P B L$ dan Media Loose Part yang disosialisaikan kepada guru-guru TK di Indonesia, sedangkan STEAM dapat dikembangkan dengan media apa saja. Desain pengembangan pembelajaran STEAM pada Kurikulum 2013 bertujuan untuk memudahkan para guru/calon guru PAUD mengidentifikasi apa dan bagaimana muatan STEAM dapat diterapkan dalam pembelajaran. Selain itu guru juga mampu mengidentifikasi kompetensi dasar dan indikator yang dapat diterapkan dalam pembelajaran STEAM tersebut sebagai pedoman proses pembelajaran, dan evaluasi.

Selanjutnya dalam pendekatan Research and Development, dibutuhkan langkah penelitian lebih lanjut. Perlu dilakukan validasi, uji coba terbatas, dan uji coba meluas untuk mengetahui keterterapan desain Pengembangan Pembelajaran STEAM AUD Kurikulum 2013.

\section{REFERENCES}

Becker, K., \& Park, K. (2011). Effects of integrative approaches among science, technology, engineering, and mathematics (STEM) subjects on students' learning: A preliminary meta-analysis. Journal of STEM Education: Innovations \& Research, 12.

Cross, C. T., Woods, T. A., \& Schweingruber, H. E. (2009). Mathematics learning in early childhood: Paths toward excellence and equity. National Academies Press.

DeJarnette, N. K. (2018). Implementing STEAM in the Early Childhood Classroom. European Journal of STEM Education, 3(3), 18.

Garbett, D. (2003). Science education in early childhood teacher education: Putting forward a case to enhance student teachers' confidence and competence. Research in Science Education, 33(4), 467481.

Kemendikbud. (2015a). Pedoman Pengembangan Tema Pembelajaran Anak Usia Dini Pendidikan (Issue 021). Direktorat Pembinaan Pendidikan Anak Usia Dini Kementerian Pendidikan dan Kebudayaan. https://drive.google.com/file/d/0B-1xIqIGe4j8c0hIYU9pcmM1YVk/view

Kemendikbud. (2015b). Kurikulum Pendidikan Anak Usia Dini Apa, Mengapa, Bagaimana. Direktorat 
Pembinaan Pendidikan Anak Usia Dini Kementerian Pendidikan dan Kebudayaan.

Munawar, M., Roshayanti, F., \& Sugiyanti, S. (2019). Implementation of STEAM (Science Technology Engineering Art Mathematics)-based early childhood education learning in Semarang City. CERIA (Cerdas Energik Responsif Inovatif Adaptif), 2(5), 276-285.

ONG, E. T., Aminah, A., IBRAHIM, M. N., ADNAN, M., SHARIFF, J., \& ISHAK, N. (2016). The effectiveness of an in-service training of early childhood teachers on STEM integration through Project-Based Inquiry Learning (PIL). Journal of Turkish Science Education, 13(special), 44-58.

PPPPTK \& PLB. (2020). Diklat Daring "STEAM bagi guru TK." https://p4tktkplb.kemdikbud.go.id/index.php/pages/struktur-organisasi/diklat-daring-steam-bagi-gurutk

Ramadlani, A. K., \& Wibisono, M. (2017). Visual literacy and character education for alpha generation. Proceedings International Seminar on Language, Education and Culture.

Saçkes, M. (2014). How often do early childhood teachers teach science concepts? Determinants of the frequency of science teaching in kindergarten. European Early Childhood Education Research Journal, 22(2), 169-184.

Sharapan, H. (2012). From STEM to STEAM: How early childhood educators can apply Fred Rogers' approach. YC Young Children, 67(1), 36.

Thuneberg, H. M., Salmi, H. S., \& Bogner, F. X. (2018). How creativity, autonomy and visual reasoning contribute to cognitive learning in a STEAM hands-on inquiry-based math module. Thinking Skills and Creativity, 29, 153-160.

Winarni, D. S. (2017). Analisis kesulitan guru PAUD dalam membelajarakan IPA pada anak usia dini. Edu Sains: Jurnal Pendidikan Sains Dan Matematika, 5(1), 12-22. 